\title{
Dynamic Efficiency of a Container Crane's Hoisting Transmission System under Hoisting Dynamic Load
}

\author{
Yuanyuan Liu, Qing Zhang, Xianrong Qin, and Yuantao Sun \\ College of Mechanical Engineering, Tongji University, Shanghai 200092, China \\ Correspondence should be addressed to Yuanyuan Liu; anneliuyuanyuan@gmail.com \\ Received 8 January 2016; Revised 16 February 2016; Accepted 17 February 2016 \\ Academic Editor: Sergio De Rosa
}

Copyright ( 2016 Yuanyuan Liu et al. This is an open access article distributed under the Creative Commons Attribution License, which permits unrestricted use, distribution, and reproduction in any medium, provided the original work is properly cited.

\begin{abstract}
The dynamic efficiency of hoisting transmission system on a container crane is fundamental for accurate efficiency prediction, while the dynamic efficiency of hoisting transmission system has not been investigated sufficiently. This paper will focus on dynamic efficiency of hoisting transmission system under hoisting dynamic load. A power loss model of gearbox was built. Then the dynamic model of gear transmission was developed including time-varying mesh stiffness and hoisting dynamic load was studied. Power loss, dynamic efficiency, and equivalent static efficiency were conducted in hoisting and lowering working conditions. The result shows that dynamic efficiency which consists of the significant lower frequency component coincided with hoisting load torque of the higher frequency component which is directly related to dynamic mesh and bearing force. And in two processes, the equivalent static efficiency in constant speed stage is min, whereas maximum value occurs in different stage. The research results lay a foundation for hoisting gear transmission dynamic efficiency analysis.
\end{abstract}

\section{Introduction}

Hoisting mechanism is a significant part of quayside container crane, and its main function is to achieve the hoisting and lowering motion of cargo. At operating time, hoisting mechanism experiences several times circulation of acceleration, constant speed, deceleration, and stop stage. Meanwhile, the changes of cargo's motion and vibrations of container crane support structure will generate additional dynamic load. So the gear transmission of hoisting mechanism is under complex working condition of which the rotation speed and load are continuously changing. The changing rotation speed and load will influence the efficiency of the gear transmission at operating time for different stages. Therefore the study on dynamic efficiency of the hoisting gear transmission system under hoisting dynamic load is essential.

According to Hohn et al. [1] as well as several other authors [2-11] the most common power loss consists of friction loss between the meshing teeth [2-4], friction loss in the rolling bearings [4-6], churning loss [7-9], and friction loss in seals [4]. In previous research [10, 11], the power loss in meshing teeth and rolling bearings is calculated by static load. However in the real situation, the mesh force and bearing force are time-varying because of the vibration of every gear. The dynamic load's effect on the efficiency of gear transmission is inevitable. As to the dynamic efficiency of a container crane's hoisting transmission system under hoisting dynamic load, it is still a blank.

Consequently, this paper will focus on the dynamic efficiency of gear transmission under hoisting dynamic load, including establishing dynamic model for gear transmission and hoisting mechanism, simulating the dynamic mesh and bearing force in hoisting and lowering working condition, and investigating the dynamic efficiency in different working conditions. The time-varying mesh stiffness and hoisting dynamic loads have also been taken into account. We have expectations to lay a foundation for hoisting gear transmission dynamic efficiency analysis.

\section{Power Loss Model}

Power loss in a gearbox can be defined as the sum of the load-dependent and load-independent power loss, as shown in Figure 1. Load-dependent losses occur in the contact of the power transmitting components. Load losses mainly depend 


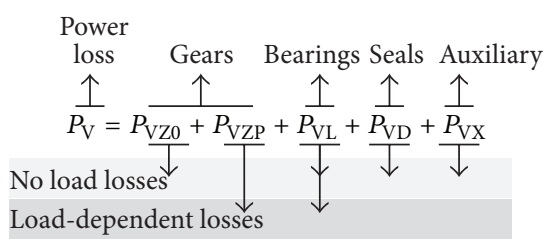

Figure 1: Power loss model.

on the transmitted torque, coefficient of friction, and sliding velocity in the contact areas of the components [1-6]. No load losses occur with the motion of mechanical components, even without torque transmission. These are mainly related to lubricant viscosity and density as well as immersion depth of the components on a sump lubricated gearbox; besides it heavily depends on operating conditions and internal housing design [7-9].

2.1. Gear Friction Power Loss. The average gear friction power loss depends on the transmitted power, the average coefficient of friction between meshing teeth, and a gear loss factor:

$$
P_{\mathrm{VZP}}=P_{\mathrm{a}} \cdot \mu_{\mathrm{mz}} \cdot H_{\mathrm{V}} \cdot
$$

The input power $\left(P_{\mathrm{a}}\right)$ is the product between the sum of the teeth normal forces project in a plane normal to the gear rotation axis and the base circle tangential speed:

$$
\begin{aligned}
P_{\mathrm{a}} & =F_{\mathrm{bt}} \cdot v_{\mathrm{tb}}, \\
F_{\mathrm{bt}} & =\frac{M_{i}}{r_{\mathrm{bt}}}, \\
v_{\mathrm{tb}} & =n_{i} \cdot \frac{\pi}{30} \cdot r_{\mathrm{bt}} .
\end{aligned}
$$

The average coefficient of friction $\mu_{\mathrm{mz}}$ was calculated according to a modified version of Schlenk's equation [1]. This equation depends on the operating conditions $\left(F_{\mathrm{bn}} / v_{\mathrm{sc}}\right)$, gear geometry $\left(l_{\min } \cdot \rho C\right)$, dynamic viscosity $(\eta)$, average surface roughness $(R a)$, and a lubricant parameter $(X L)$. The lubricant parameter is $X L=1$ for nonadditivated mineral oils:

$$
\mu_{\mathrm{mz}}=0.048 \cdot\left(\frac{F_{\mathrm{bt}} / b}{v_{\mathrm{sc}} \cdot \rho C}\right)^{0.2} \cdot \eta^{-0.05} \cdot R a^{0.25} \cdot X L .
$$

$H_{\mathrm{V}}$ represents the gear loss factor which is determined according to (6). Equation (6) initially proposed by Ohlendorf is mostly valid for spur gears. One has

$$
\begin{aligned}
H_{\mathrm{V}}= & (1+u) \frac{\pi}{z_{1}} \frac{1}{\cos \beta_{\mathrm{b}}}\left(1-\varepsilon_{\alpha}+\varepsilon_{1}^{2}+\varepsilon_{2}^{2}\right) \\
& \cdot \frac{-b \pm \sqrt{b^{2}-4 a c}}{2 a} .
\end{aligned}
$$

2.2. Rolling Bearing Power Loss. The tapered roller and deep groove ball bearings power loss were calculated according to the new SKF model [5], using

$$
M=M_{\mathrm{rr}}+M_{\mathrm{sl}}+M_{\mathrm{drag}}+M_{\mathrm{seal}} .
$$

The calculation of the frictional torque in the rolling bearing takes into account four different torque loss sources: $M$ is the total frictional torque $(\mathrm{Nmm}), M_{\mathrm{rr}}$ is the rolling friction torque loss torque, $M_{\mathrm{sl}}$ is the sliding frictional torque, and $M_{\text {seal }}$ is the frictional torque of the seals. $M_{\text {drag }}$ is the frictional torque of drag losses, churning, splashing, and so forth. The rolling and sliding components of the rolling bearings torque loss are dependent on dimensions, geometry, and operating conditions. The sliding friction torque is also affected by two correction parameters that take into account the effects of kinematic starvation and inlet shear heating.

2.3. Seals Power Loss. The power loss generated by the seals was calculated using the well-known Simrit equation:

$$
P_{\mathrm{VD}}=7.69 \times 10^{-6} \cdot d_{\mathrm{sh}}^{2} \cdot n_{i} .
$$

In (8), $d_{\mathrm{sh}}$ is the shaft diameter in $\mathrm{mm}$ and $n$ is the rotational speed in rpm.

2.4. Gear Churning Loss. For splash-lubricated gears, oil churning is usually considered as a major source of power loss which is strongly related to the fluid circulations generated by rotating gears partly immersed in a lubricant.

The churning loss generated by a gear can be accurately calculated as the sum of the individual churning loss caused by each pinion/wheel [8]. In the present study the swell effect was disregarded, since the only gear pair that was on a counter-clockwise configuration had a speed ratio that was not large enough to generate any significant additional power loss. The gear churning loss model developed by Changenet and Velex [8] was implemented and the gear churning losses were calculated for all the experimental conditions. by

On this gear churning loss model the torque loss is given

$$
C_{\mathrm{ch}}=\frac{1}{2} \cdot \rho_{\mathrm{oil}} \cdot \omega^{2} \cdot R_{\mathrm{p}}^{3} \cdot S_{\mathrm{m}} \cdot C_{\mathrm{m}}
$$

where $C_{m}$ is the drag dimensionless group, $S_{m}$ is the immersed surface of the pinion/wheel (flank and teeth), $R_{\mathrm{p}}$ is the pinion reference radius, $\omega$ is the angular frequency, and $\rho$ is the bulk density of the lubricant at the working temperature.

\section{Dynamic Modeling for Hoisting Transmission System}

3.1. Dynamic Model for Hoisting Gear Transmission System. The hoisting transmission system of a $40 \mathrm{t}$ container crane was selected. Figure 2 shows a schematic view of the hoisting transmission system. This system has two-stage planet gears with sun gear as input, carrier as output, and ring gear as fixation. Three planets in every stage are used for power distribution and load sharing. Through the gear transmission, the input torque $T_{\text {out }}$ provided by the motor is transformed as the output torque $T_{\text {out }}$ of winding drum. The wire rope tension $F_{\text {out }}$ from output torque which equals hoisting dynamic load induces the motion of cargo. 


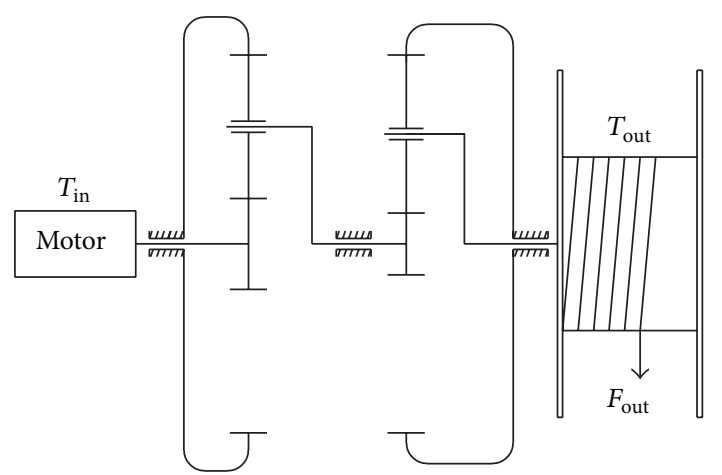

Figure 2: Schematic view of the lifting transmission system.

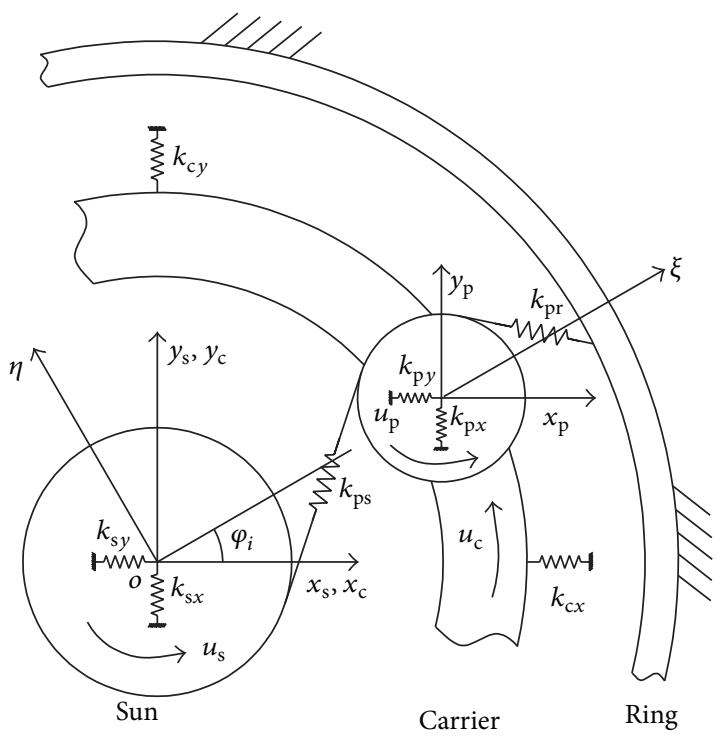

FIgURe 3: Dynamic model of planetary gear system.

Planet not only rotates on its own axis but also revolves around the axis of sun with planetary carrier. Therefore the dynamic model of planetary gear was built at the moving coordinates $o \xi \eta$ with planetary carrier. A translationrotation coupling dynamic model of transmission system was established considering the time-varying mesh stiffness of gear pairs and support stiffness of every gear as shown in Figure 3. The direction of input torque is the positive direction, and translational direction is determined by the respective coordinates.

$k_{\mathrm{ps}}, k_{\mathrm{pr}}$ are mesh stiffness of gear pair. $k_{j x}, k_{j y}$ are support stiffness of every component, $j=\mathrm{s}, \mathrm{p}, \mathrm{c} . u_{\mathrm{s}}, u_{\mathrm{p}}$, and $u_{\mathrm{c}}$ are rotational displacement. $x_{j}, y_{j}$ are translational displacement. $\varphi_{i}$ is the position angle of planet $i, i=1,2,3 . \alpha$ is working pressure angle and is generally $20^{\circ}$.

Elastic deformation on meshing line of sun and planet $\delta_{\text {spi }}$ can be expressed in (10). Elastic deformation on meshing line of ring and planet $\delta_{\mathrm{rpi}}$ can be expressed in (11). Elastic deformation of planet relative to carrier on translational and rotational directions $\delta_{c i x}, \delta_{c i y}$, and $\delta_{c i u}$ can be expressed in (12). One has

$$
\begin{aligned}
& \delta_{\mathrm{sp} i}=\left(x_{i}-x_{\mathrm{s}}\right) \sin \varphi_{\mathrm{s} i}+\left(y_{\mathrm{s}}-y_{i}\right) \cos \varphi_{\mathrm{s} i}+u_{\mathrm{s}}+u_{i}, \\
& \delta_{\mathrm{rp} i}=\left(x_{i}-x_{\mathrm{r}}\right) \sin \varphi_{\mathrm{r} i}+\left(y_{\mathrm{r}}-y_{i}\right) \cos \varphi_{\mathrm{r} i}+u_{\mathrm{r}}-u_{i}, \\
& \delta_{\mathrm{c} i x}=x_{\mathrm{c}}-x_{i}-u_{\mathrm{c}} \sin \varphi_{i}, \\
& \delta_{\mathrm{c} i y}=y_{\mathrm{c}}-y_{i}+u_{\mathrm{c}} \cos \varphi_{i}, \\
& \delta_{\mathrm{c} i u}=\left(x_{i}-x_{\mathrm{c}}\right) \sin \varphi_{i}+\left(y_{\mathrm{c}}-y_{i}\right) \cos \varphi_{i}+u_{\mathrm{c}} .
\end{aligned}
$$

Here $\varphi_{\mathrm{si}}=\varphi_{\mathrm{s}}-\alpha, \varphi_{\mathrm{ri}}=\varphi_{\mathrm{r}}+\alpha$.

Multiplying the elastic deformation on meshing line by mesh stiffness, meshing force can be obtained. Bearing force can also be calculated with multiplying the translational displacement by support stiffness. According to force analysis of every component, differential equation of translationrotation coupling vibration can be induced in

$$
\begin{aligned}
& m_{\mathrm{s}}\left(\ddot{x}_{\mathrm{s}}-2 \omega_{\mathrm{c}} \dot{y}_{\mathrm{s}}-\omega_{\mathrm{c}}^{2} x_{\mathrm{s}}-\dot{\omega}_{\mathrm{c}} y_{\mathrm{s}}\right)-\sum_{i=1}^{3} k_{\mathrm{sp} i} \delta_{\mathrm{sp} i} \sin \varphi_{\mathrm{s} i} \\
& +k_{\mathrm{s} x} x_{\mathrm{s}}=0, \\
& m_{\mathrm{s}}\left(\ddot{y}_{\mathrm{s}}+2 \omega_{\mathrm{c}} \dot{x}_{\mathrm{s}}-\omega_{\mathrm{c}}^{2} y_{\mathrm{s}}+\dot{\omega}_{\mathrm{c}} x_{\mathrm{s}}\right)+\sum_{i=1}^{3} k_{\mathrm{sp} i} \delta_{\mathrm{sp} i} \cos \varphi_{\mathrm{s} i} \\
& +k_{\mathrm{s} y} x_{\mathrm{s}}=0 \\
& \left(\frac{I_{\mathrm{s}}}{r_{\mathrm{s}}^{2}}\right) \ddot{u}_{\mathrm{s}}+\sum_{i=1}^{3} k_{\mathrm{sp} i} \delta_{\mathrm{sp} i}+k_{\mathrm{st}} u_{\mathrm{s}}=\frac{T_{\mathrm{in}}}{r_{\mathrm{s}}}, \\
& m_{\mathrm{p}}\left(\ddot{x}_{i}-2 \omega_{\mathrm{c}} \dot{y}_{i}-\omega_{\mathrm{c}}^{2} x_{i}-\dot{\omega}_{\mathrm{c}} y_{i}\right)+k_{\mathrm{sp} i} \delta_{\mathrm{sp} i} \sin \varphi_{\mathrm{s} i} \\
& +k_{\mathrm{rpi}} \delta_{\mathrm{rpi}} \sin \varphi_{\mathrm{ri}}-k_{\mathrm{p}} \delta_{\mathrm{cix}}=0, \\
& m_{\mathrm{p}}\left(\ddot{y}_{i}+2 \omega_{\mathrm{c}} \dot{x}_{i}-\omega_{\mathrm{c}}^{2} y_{i}+\dot{\omega}_{\mathrm{c}} x_{i}\right)-k_{\mathrm{sp} i} \delta_{\mathrm{sp} i} \cos \varphi_{\mathrm{s} i} \\
& -k_{\mathrm{rpi}} \delta_{\mathrm{rp} i} \cos \varphi_{\mathrm{ri} i}-k_{\mathrm{p}} \delta_{\mathrm{ciy}}=0, \\
& \left(\frac{I_{\mathrm{p}}}{r_{\mathrm{p}}^{2}}\right) \ddot{u}_{\mathrm{p}}+k_{\mathrm{sp} i} \delta_{\mathrm{sp} i}-k_{\mathrm{rp} i} \delta_{\mathrm{rp} i}=0 \text {, } \\
& m_{\mathrm{c}}\left(\ddot{x}_{\mathrm{c}}-2 \omega_{\mathrm{c}} \dot{y}_{\mathrm{c}}-\omega_{\mathrm{c}}^{2} x_{\mathrm{c}}-\dot{\omega}_{\mathrm{c}} y_{\mathrm{c}}\right)+\sum_{i=1}^{3} k_{\mathrm{p}} \delta_{c i x} \\
& +k_{c x} x_{c}=0, \\
& m_{\mathrm{c}}\left(\ddot{y}_{\mathrm{c}}+2 \omega_{\mathrm{c}} \dot{x}_{\mathrm{c}}-\omega_{\mathrm{c}}^{2} y_{\mathrm{c}}+\dot{\omega}_{\mathrm{c}} x_{\mathrm{c}}\right)+\sum_{i=1}^{3} k_{\mathrm{p}} \delta_{\mathrm{c} i y} \\
& +k_{c y} y_{\mathrm{c}}=0 \text {, } \\
& \left(\frac{I_{\mathrm{c}}}{r_{\mathrm{c}}^{2}}\right) \ddot{u}_{\mathrm{c}}+\sum_{i=1}^{3} k_{\mathrm{p}} \delta_{c i u}+k_{\mathrm{ct}}\left(u_{\mathrm{c}}-u_{\mathrm{s}}^{\prime}\right)=0,
\end{aligned}
$$




$$
\begin{gathered}
\left(\frac{I_{\mathrm{s}}^{\prime}}{\left(r_{\mathrm{s}}^{\prime}\right)^{2}}\right) \ddot{u}_{\mathrm{s}}^{\prime}+\sum_{i=1}^{3} k_{\mathrm{sp} i}^{\prime} \delta_{\mathrm{sp} i}^{\prime}+k_{\mathrm{st}}^{\prime}\left(u_{\mathrm{s}}^{\prime}-u_{\mathrm{c}}\right)=0, \\
\vdots \\
\left(\frac{I_{\mathrm{c}}^{\prime}}{\left(r_{\mathrm{c}}^{\prime}\right)^{2}}\right) \ddot{u}_{\mathrm{c}}^{\prime}+\sum_{i=1}^{3} k_{\mathrm{p}}^{\prime} \delta_{\mathrm{ciu}}^{\prime}+k_{\mathrm{ct}}^{\prime} u_{\mathrm{c}}^{\prime}=-\frac{T_{\mathrm{out}}}{r_{\mathrm{c}}^{\prime}}
\end{gathered}
$$

In (13), the differential equations of two stages are similar. The differences are in the rotation direction of sun gear and carrier. And the superscript "' " stands for the parameters of the second-stage planet gears.

$\omega_{c}$ is rotational velocity of carrier. $m_{j}$ is the mass of gear, $I_{j}$ is the moment of inertia, and $r_{j}$ is the base circle.

For simplified representation, a matrix equation can be expressed as

$$
\mathbf{M} \ddot{\mathbf{x}}+\omega_{\mathrm{c}} \mathbf{G} \dot{\mathbf{x}}+\left(\mathbf{K}_{b}+\mathbf{K}_{g}+\omega_{\mathrm{c}}^{2} \mathbf{K}_{\Omega}+\dot{\omega}_{\mathrm{c}} \mathbf{K}_{t}\right) \mathbf{x}=\mathbf{F},
$$

where $\mathbf{M}$ is generalized mass matrix, $\mathbf{G}$ is gyroscopic matrix, $\mathbf{K}_{b}$ support stiffness matrix of bearings, $\mathbf{K}_{g}$ is mesh stiffness matrix, $\mathbf{K}_{\Omega}$ is centripetal stiffness matrix, $\mathbf{K}_{t}$ is tangential stiffness matrix, $\mathbf{F}$ is external excitation, and $\mathbf{x}$ is generalized degrees of freedom, $\mathbf{x}=\left[x_{s}, y_{s}, u_{s}, x_{1}, y_{1}, u_{1}, \ldots, x_{3}, y_{3}, u_{3}, x_{c}, y_{c}, u_{c}, x_{s}^{\prime}, y_{s}^{\prime}, u_{s}^{\prime}, x_{1}^{\prime}\right.$, $\left.y_{1}^{\prime}, u_{1}^{\prime}, \ldots, x_{3}^{\prime}, y_{3}^{\prime}, u_{3}^{\prime}, x_{c}^{\prime}, y_{c}^{\prime}, u_{c}^{\prime}\right]^{\mathrm{T}}$.

3.2. Mesh Stiffness Excitation. Stiffness excitation is engaged by the change in the number of meshing gears and is dynamic to the gear transmission system. Spur gear's mesh stiffness can be assumed as the rectangular wave. Then it can be expressed in the form of Fourier series expansion as follows:

$$
\begin{aligned}
k(t) & =k_{\mathrm{s} \min }+\left(k_{\mathrm{s} \max }-k_{\mathrm{s} \min }\right)\left(e_{\mathrm{s}}-1\right) \\
+ & \sum_{i=1}^{n} \frac{k_{\mathrm{s} \max }-k_{\mathrm{s} \min }}{i \pi} \\
\cdot & {\left[\sin 2 \pi i\left(\gamma+e_{\mathrm{s}}-1-\frac{t}{T}\right)-\sin 2 \pi i\left(\gamma-\frac{t}{T}\right)\right], }
\end{aligned}
$$

where $k_{\mathrm{s} \max }, k_{\mathrm{s} \min }$ are the max and min mesh stiffness, $\gamma$ is mesh phase angle, $e_{\mathrm{s}}$ is coincidence, and $T$ is mesh period.

\section{Hoisting Dynamic Load}

4.1. Dynamic Model of Hoisting Mechanism. Selecting the hoisting mechanism of a $40 \mathrm{t}$ container crane as research object, the dynamic model of hoisting mechanism shown in Figure 4 was simplified as 6 DOF. Downward direction is positive. The boom of container crane was assumed as 5 DOF, pull rod was assumed as springs $k_{1}, k_{2}$, and wire rope was assumed as a spring $k_{3}$ considering damping effects. $s(t)$ is winding displacement of drum, which is directly linking to the cargo.
According to the dynamic model of lifting system, the differential equation can be expressed as follows:

$$
\begin{aligned}
& {\left[\begin{array}{cc}
\mathbf{M}_{1} & 0 \\
0 & m_{6}
\end{array}\right] \ddot{\mathbf{X}}+\left[\begin{array}{cc}
\mathbf{C}_{1} & -c \\
-c & c
\end{array}\right] \dot{\mathbf{X}}+\left[\begin{array}{cc}
\mathbf{K}_{1} & -k_{3} \\
-k_{3} & k_{3}
\end{array}\right] \mathbf{X}} \\
& \quad=\left[\begin{array}{c}
\mathbf{F}_{1} \\
f_{2}(t)
\end{array}\right],
\end{aligned}
$$

where $\mathbf{M}_{1}$ is mass matrix of support structure, $\mathbf{C}_{1}$ is damping matrix of support structure, $\mathbf{K}_{1}$ is stiffness matrix of support structure, which can be obtained by flexibility method, and $k_{3}$ is the stiffness of wire rope, which can be expressed by function $k_{3}=E A / l$ and presents the time-varying characteristics when the length changes in operation time. In the function, $E$ is elasticity modulus of wire rope. $A$ is crosssectional area of wire rope. $l$ is the length of wire rope, which is time-varying. $c$ is the damping of wire rope. And the damping function is $c=0.1 \cdot c_{e}=0.1 \cdot 2 \cdot \sqrt{m \cdot k / 3}$.

The hoisting process of container crane can be divided into two stages. The first stage is from the beginning of drum winding to the moment when the cargo was lifted off the ground. In this stage, cargo $m_{6}$ was on the ground and did not have vibration. Only the support structure had vibration. Then the differential equation in the first stage is shown as follows:

$$
\begin{aligned}
\mathbf{M}_{1} \ddot{\mathbf{X}}+\mathbf{C}_{1} \dot{\mathbf{X}}+\mathbf{K}_{1} \mathbf{X} & =\mathbf{F}_{1}, \\
\mathbf{F}_{1} & =\left[\begin{array}{c}
\mathbf{0}_{4 \times 1} \\
k_{3} \cdot s(t)+c \cdot \dot{s}(t)
\end{array}\right] .
\end{aligned}
$$

In the second stage of hoisting process, the cargo was lifted off the ground and involved in the vibration of the entire system. There, the differential equation in the second stage is expressed in (16). Here,

$$
f_{2}(t)=m_{6} \cdot g-k_{3} \cdot s(t)-c \cdot \dot{s}(t) .
$$

For the lowering process of container crane, the motion equation is the same with the second stage of hoisting process (16). The only difference between two processes is the opposite direction of winding displacement.

Solving the differential equation, acceleration, velocity, and displacement of every DOF can be obtained. Meanwhile, we can gain the hoisting dynamic load on the wire rope. The hoisting dynamic load on the wire rope directly impacts on the drum and causes load torque of gear transmission system. The design parameters of hoisting mechanism are listed in Table 1.

In the hoisting and lowering working condition, the times of acceleration and deceleration stage are generally $2 \mathrm{~s}$. For simplified simulation, the time of constant speed stage is set as $4 \mathrm{~s}$. Therefore the input speed of gear transmission system in hoisting working circulation is shown in Figure 5. The input speed curve is smooth without considering the speed fluctuation of motor. The lowering process differs from hoisting process in the direction of input speed. 


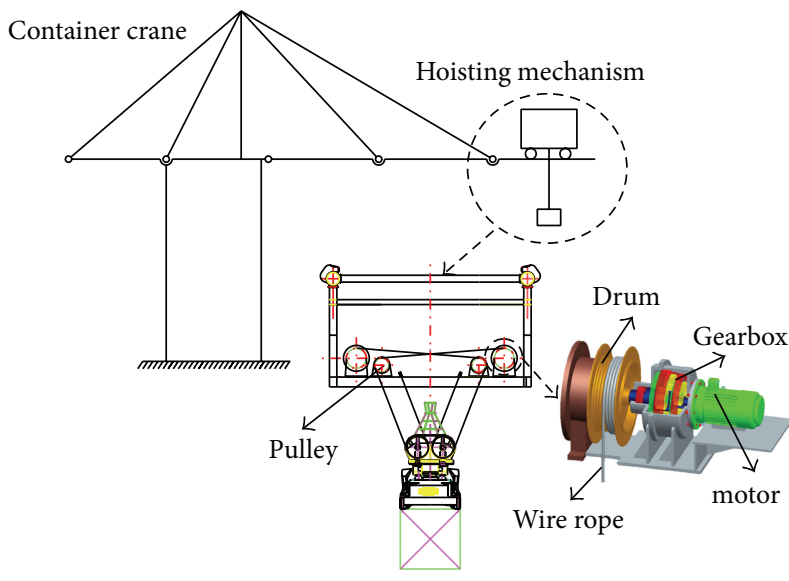

(a) Schematic view

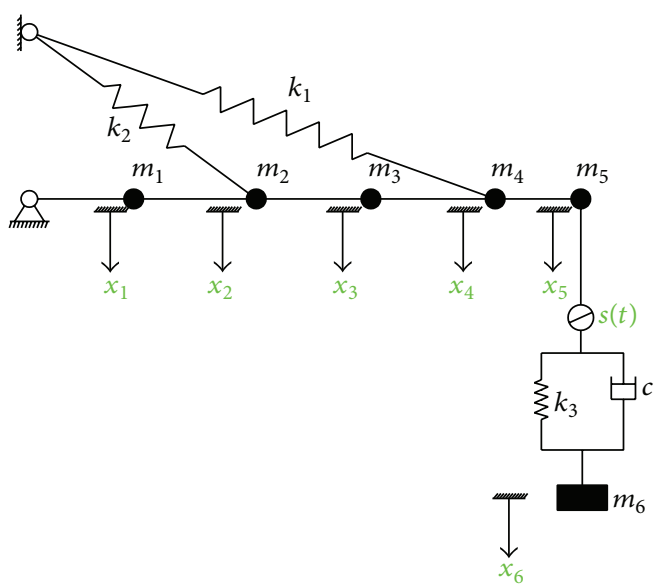

(b) Dynamic model

FIGURE 4: Schematic view and dynamic model for hoisting mechanism.

TABLE 1: Design parameters of hoisting mechanism.

\begin{tabular}{lc}
\hline Parameter & Value \\
\hline Mass of cargo $(\mathrm{kg})$ & 40000 \\
Stiffness of wire rope $(\mathrm{N} / \mathrm{m})(l=40 \mathrm{~m})$ & $4.02 e 7$ \\
Damping of wire rope $(\mathrm{N} \cdot \mathrm{s} / \mathrm{m})(l=40 \mathrm{~m})$ & $2.68 e 4$ \\
Radius of drum $(\mathrm{m})$ & 0.58 \\
Input speed $(\mathrm{rpm})$ & $0-960$ \\
Quantity of gearboxes & 4 \\
Total transmission ratio & 36.720
\end{tabular}

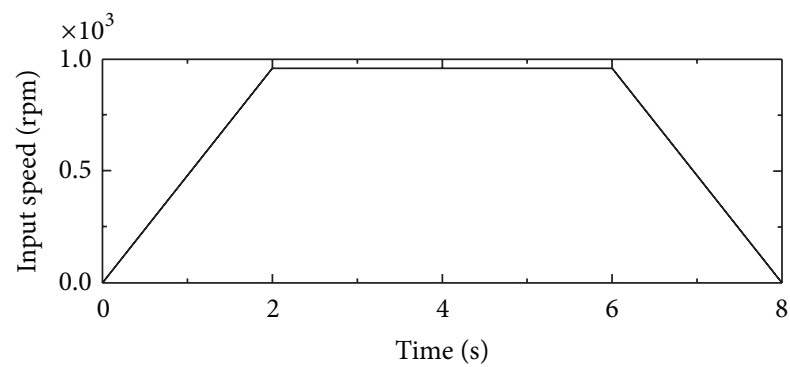

FIGURE 5: Input speed of gear transmission system in rising working condition.

4.2. Hoisting Dynamic Load Torque. By solving differential motion equations using numerical method, the time history of hoisting load torque of gear transmission system in two working conditions was obtained as shown in Figure 6. For hoisting process the load torque is gradually increasing from zero at first and then vibrates at a particular scope. There is a little difference on vibration amplitude between three stages. Acceleration stage has maximum value of torque, and deceleration stage has minimum value.

For lowering process, load torque begins at the value of cargo' weight and varies with the vibrations of cargo. There is also difference on vibration amplitude between three stages. By comparison with hoisting process, the maximum value of

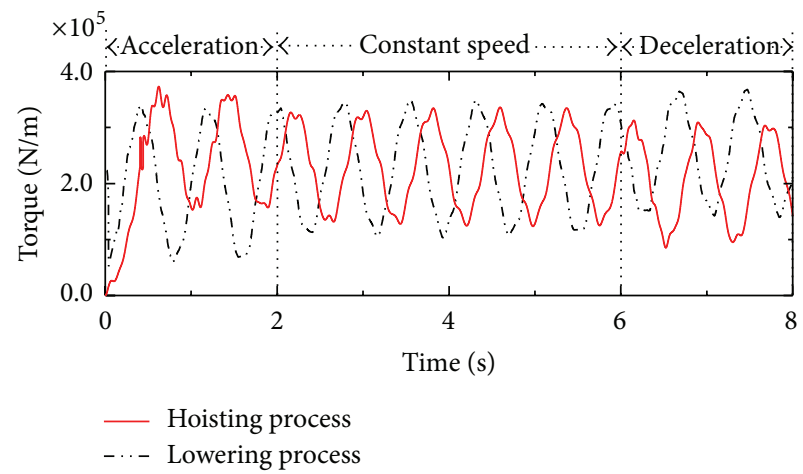

FIGURE 6: Hoisting dynamic load torque of gear transmission system.

torque in lowering working condition occurs in deceleration stage and minimum value exits in acceleration stage.

\section{Numerical Results and Discussion}

The numerical solution procedure is detailed in Figure 7. It combines a dynamic model for hoisting mechanism to obtain the load torque of gear transmission system under hoisting dynamic load, a gear transmission system model aimed at simulating dynamic parameters for efficiency analysis and a power loss model for dynamic efficiency calculation.

5.1. Input Power. From load torque shown in Figure 6 and input speed shown in Figure 5, we can obtain the input power of the gear transmission shown in Figure 8. The input power is time-varying. And the changing trend of input power coincides with the load torque, especially in constant speed stage. The total input power varies directly as the input speed, with load torque being constant. Because of the increasing input speed in acceleration stage, the total input power is gradually increasing and the amplitude becomes larger. For deceleration stage, the values are getting smaller. The phase 




FIGURE 7: Numerical simulation flowchart.

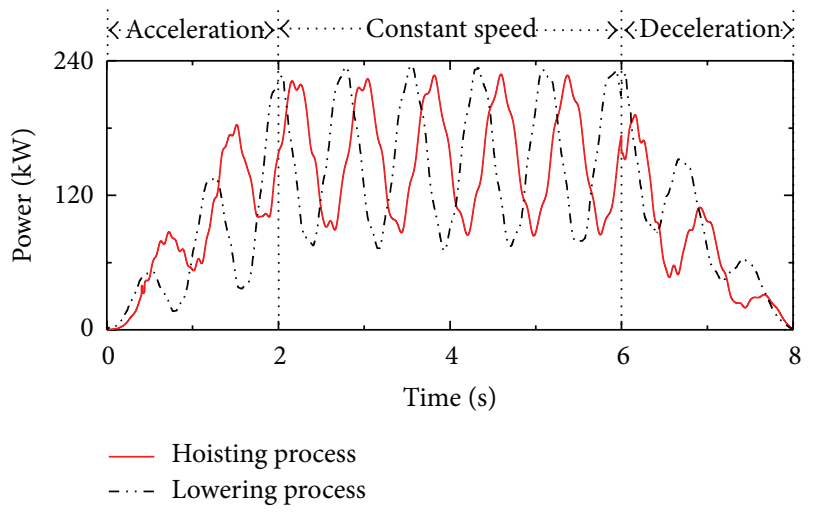

FIGURE 8: Time history of input power of the gear transmission.

difference of power curve between hoisting and lowering process is the same with the load torque.

5.2. Power Loss. Based on power loss model of gear transmission, the total power loss of the gear transmission can be calculated by gear friction power loss, bearing power loss, churning power loss, and seals power loss. Figure 9 shows the power loss of gear transmission. The time history is a constant value added with higher frequency component. The higher frequency component is caused by the dynamic mesh force and bearing force. The constant value is determined by churning loss and seals power loss that is directly related to input speed.

The power loss in hoisting process is distinguished from lowering process only by the higher frequency component. The average value in lowering process is bigger than hoisting process, for the higher frequency component varying greatly in lowering process.

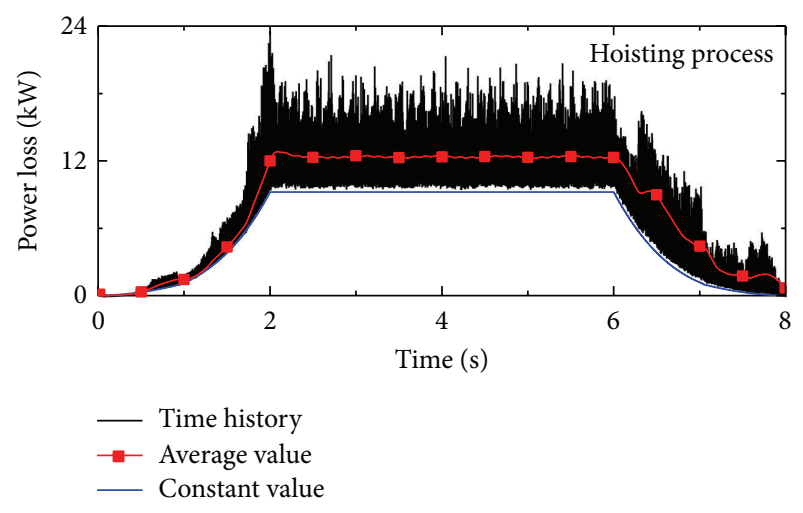

(a) Power loss in hoisting process

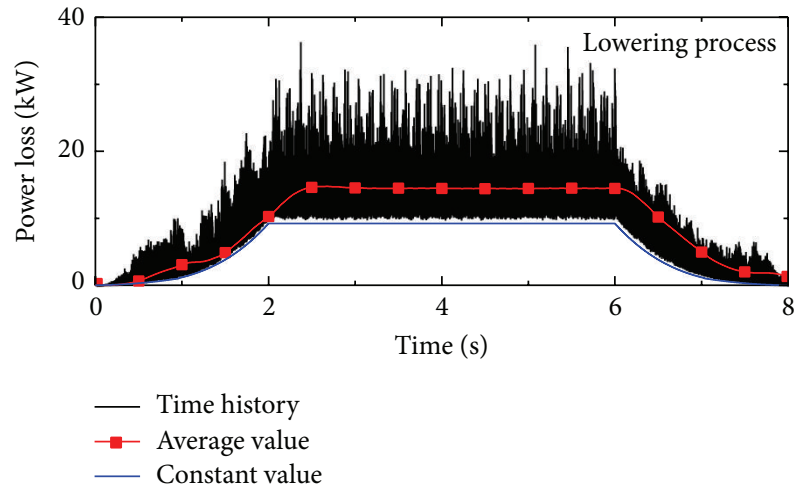

(b) Power loss in lowering process

Figure 9: Power loss of the gear transmission.

5.3. Dynamic Efficiency. Figure 10 describes the time-varying efficiency of the hoisting gear transmission in hoisting and lowering working condition. The changing trend of dynamic efficiency is also similar to the hoisting dynamic load. Based on the lower frequency component of changing trend, the time history is superimposed with higher frequency component.

In acceleration stage of hoisting process, the variation amplitude of higher frequency component is smaller. But it increases in constant speed stage and varies greatly in deceleration stage. By comparison, dynamic efficiency varies significantly in acceleration and thus decreases in constant speed and deceleration stage. As shown in Figure 10, the maximum value of dynamic efficiency in two working conditions occurs in the position when the motor almost ceased.

5.4. Equivalent Static Efficiency. In order to know the equivalent static efficiency in every working stage, the integral average is employed. Equivalent static efficiency is shown in Table 2. From the data, the equivalent static efficiency in every stage of hoisting process is smaller than lowering process for efficiency directly relating to power loss. In hoisting working condition, the acceleration stage has the max efficiency, and constant speed stage has the min efficiency. On the contrary, the deceleration stage has the max efficiency and 


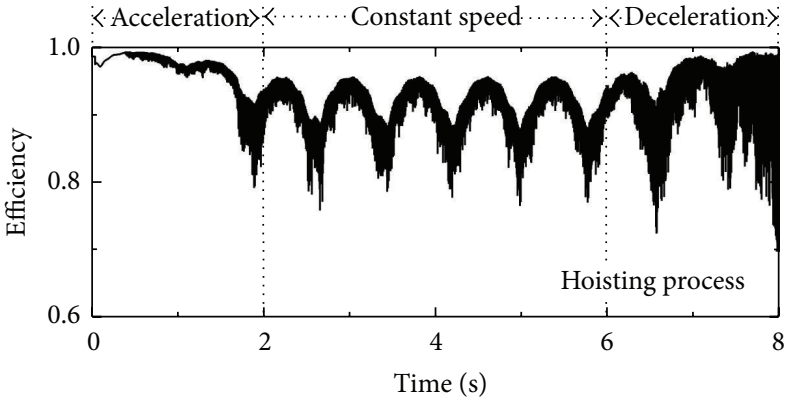

(a) Dynamic efficiency in hoisting process

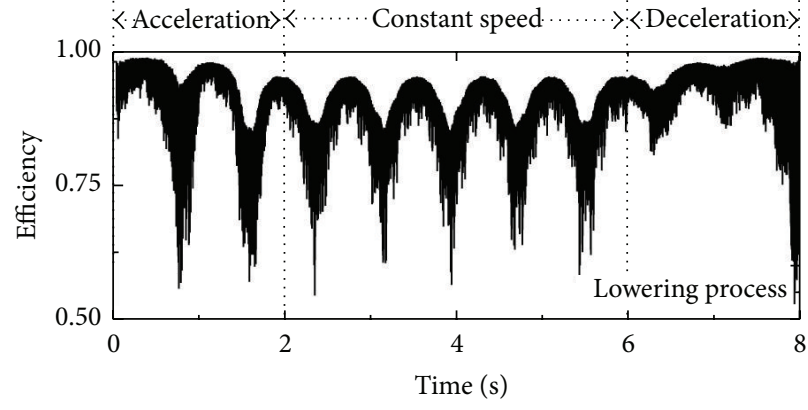

(b) Dynamic efficiency in lowering process

Figure 10: Dynamic efficiency of the gear transmission.

TABLE 2: Equivalent static efficiency of the gear transmission.

\begin{tabular}{lcc}
\hline Stage & Hoisting process & Lowering process \\
\hline Acceleration & $96.53 \%$ & $92.00 \%$ \\
Constant speed & $91.14 \%$ & $89.03 \%$ \\
Deceleration & $92.92 \%$ & $93.85 \%$ \\
A working circulation & $92.92 \%$ & $90.98 \%$ \\
\hline
\end{tabular}

constant speed stage has the min efficiency in falling working condition.

\section{Conclusions}

This paper analyzed the dynamic efficiency of hoisting gear transmission under hoisting dynamic load. The dynamic model for gear transmission and hoisting mechanism is developed by considering hoisting dynamic load. Dynamic efficiency analysis in hoisting and lowering working condition is carried out. The conclusions of this study are as follows:

(1) The time history of power loss is a constant value added with higher frequency component. The higher frequency component is caused by the dynamic mesh force and bearing force. The constant value is determined by churning loss and seals power loss which is directly related to input speed.

(2) The changing trend of dynamic efficiency is also similar to the hoisting dynamic load. Based on the lower frequency component of changing trend, the time history is superimposed with higher frequency component which is directly related to dynamic mesh and bearing force.

(3) In hoisting process, the dynamic efficiency varies greatly in deceleration stage. By comparison, the variation amplitude of efficiency is significant in acceleration stage of lowering process.

(4) In hoisting and lowering working condition, the equivalent static efficiency in constant speed stage is min, whereas max value occurs in different stage.

\section{Competing Interests}

The authors declare that there is no conflict of interests regarding the publication of this paper.

\section{Acknowledgments}

This work was supported by a grant from the Ministry of Industry and Information Technology of China (2013 Intelligent Manufacturing Equipment Development Projects) (no. [2013]2519) and the National Natural Science Foundation of China (nos. 51205292 and 51075304).

\section{References}

[1] B. R. Hohn, K. Michaelis, and T. Vollmer, "Thermal rating of gear drives: balance between power loss and heat dissipation," AGMA Technical Paper, 1996.

[2] C. M. C. G. Fernandes, P. M. T. Marques, R. C. Martins, and J. H. O. Seabra, "Gearbox power loss. Part II: friction losses in gears," Tribology International, vol. 88, pp. 309-316, 2015.

[3] C. M. C. G. Fernandes, P. M. T. Marques, R. C. Martins, and J. H. Seabra, "Gearbox power loss. Part III: application to a parallel axis and a planetary gearbox," Tribology International, vol. 88, pp. 317-326, 2015.

[4] B. R. Höhn, K. Michaelis, and M. Hinterstoißer, "Optimization of gearbox efficiency," Goriva I Maziva, vol. 48, no. 4, pp. 441480, 2009.

[5] C. M. C. G. Fernandes, P. M. T. Marques, R. C. Martins, and J. H. O. Seabra, "Gearbox power loss. Part I: losses in rolling bearings," Tribology International, vol. 88, pp. 298-308, 2015.

[6] SKF General Catalogue 6000 EN, SKF Group, Goteborg, Sweden, 2005.

[7] F. Concli and C. Gorla, "Computational and experimental analysis of the churning power losses in an industrial planetary speed reducer," in Proceedings of the 9th International Conference on Advances in Fluid Mechanics-Advances in Fluid Mechanics IX, vol. 74 of WIT Transactions on Engineering Sciences, 2012.

[8] C. Changenet and P. Velex, "A model for the prediction of churning losses in geared transmissions-preliminary results," Journal of Mechanical Design, vol. 129, no. 1, pp. 128-133, 2007.

[9] P. M. T. Marques, C. M. C. G. Fernandes, R. C. Martins, and J. H. O. Seabra, "Power losses at low speed in a gearbox lubricated 
with wind turbine gear oils with special focus on churning losses," Tribology International, vol. 62, pp. 186-197, 2013.

[10] H. Xu, A. Kahraman, N. E. Anderson, and D. G. Maddock, "Prediction of mechanical efficiency of parallel-axis gear pairs," Journal of Mechanical Design, vol. 129, no. 1, pp. 58-68, 2007.

[11] G. Jia-Shun, W. San-Min, and Y. Ru, "Dynamic efficiency investigation of the transmission of tilt-totor," Journal of Aerospace Power, vol. 25, no. 8, pp. 1894-1899, 2010. 


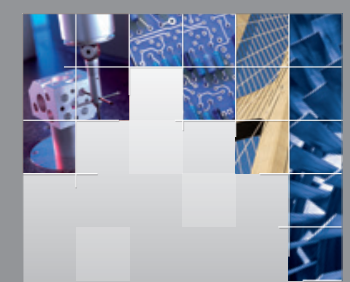

\section{Enfincering}
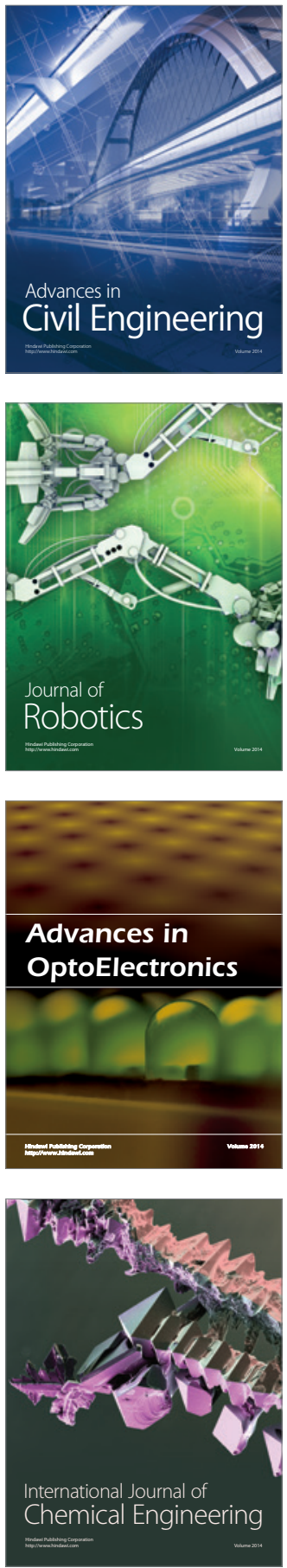

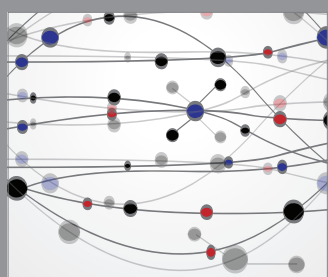

The Scientific World Journal

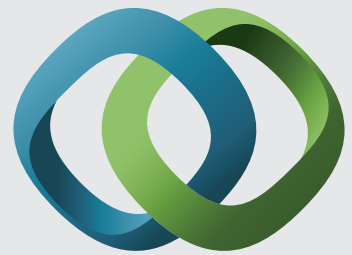

\section{Hindawi}

Submit your manuscripts at

http://www.hindawi.com
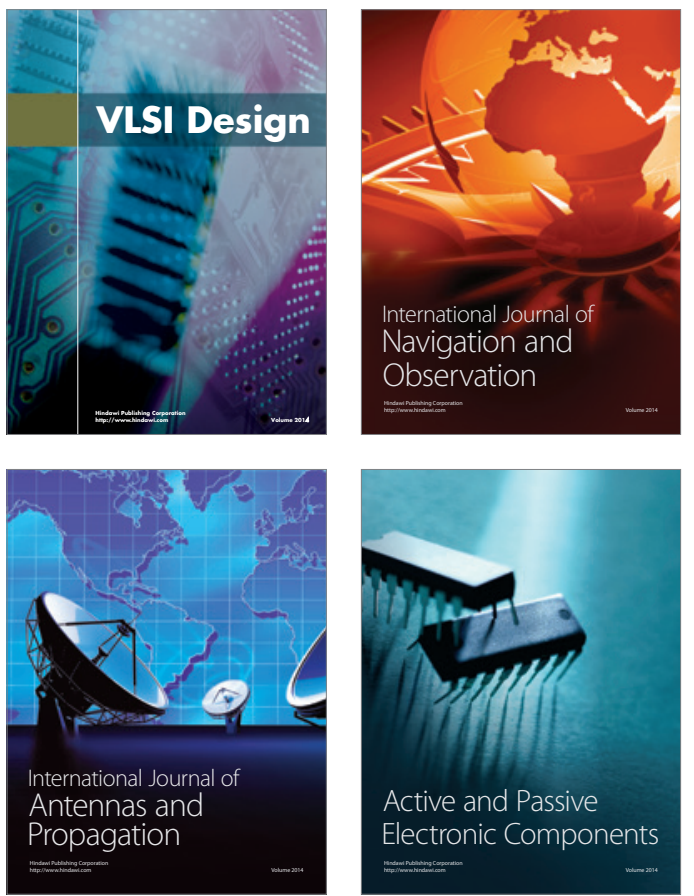
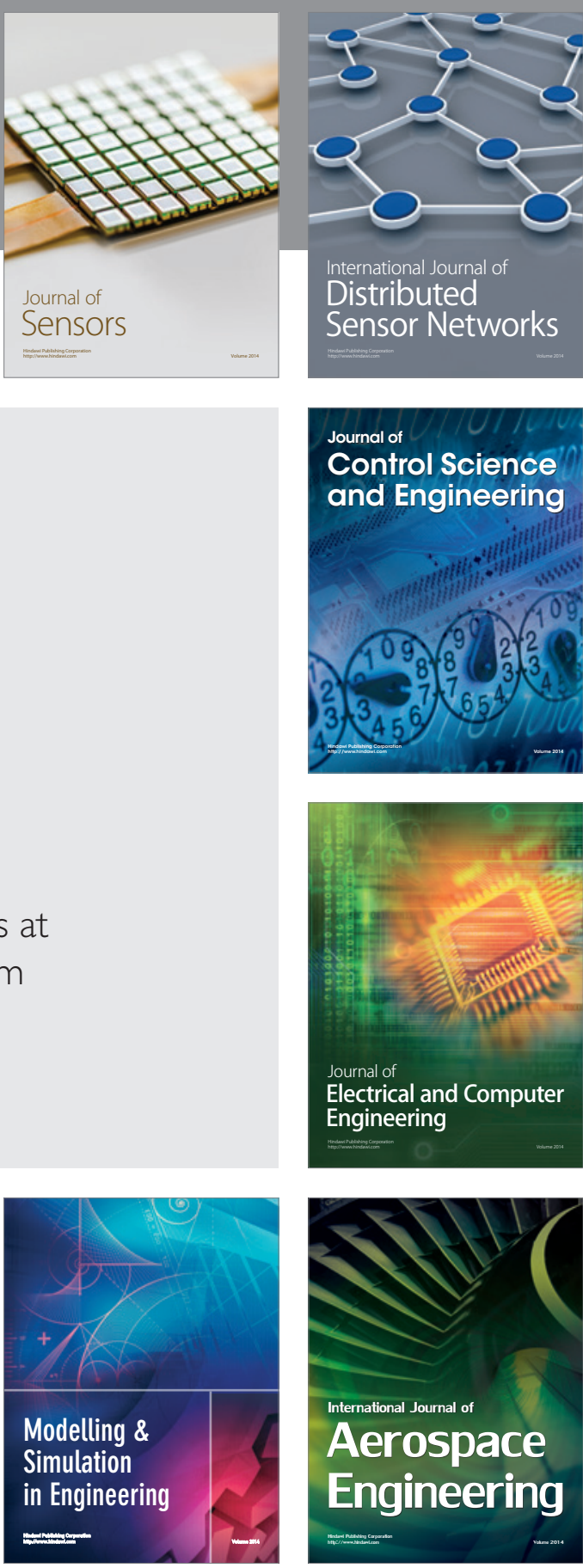

International Journal of

Distributed

Sensor Networks

Journal of

Control Science

and Engineering
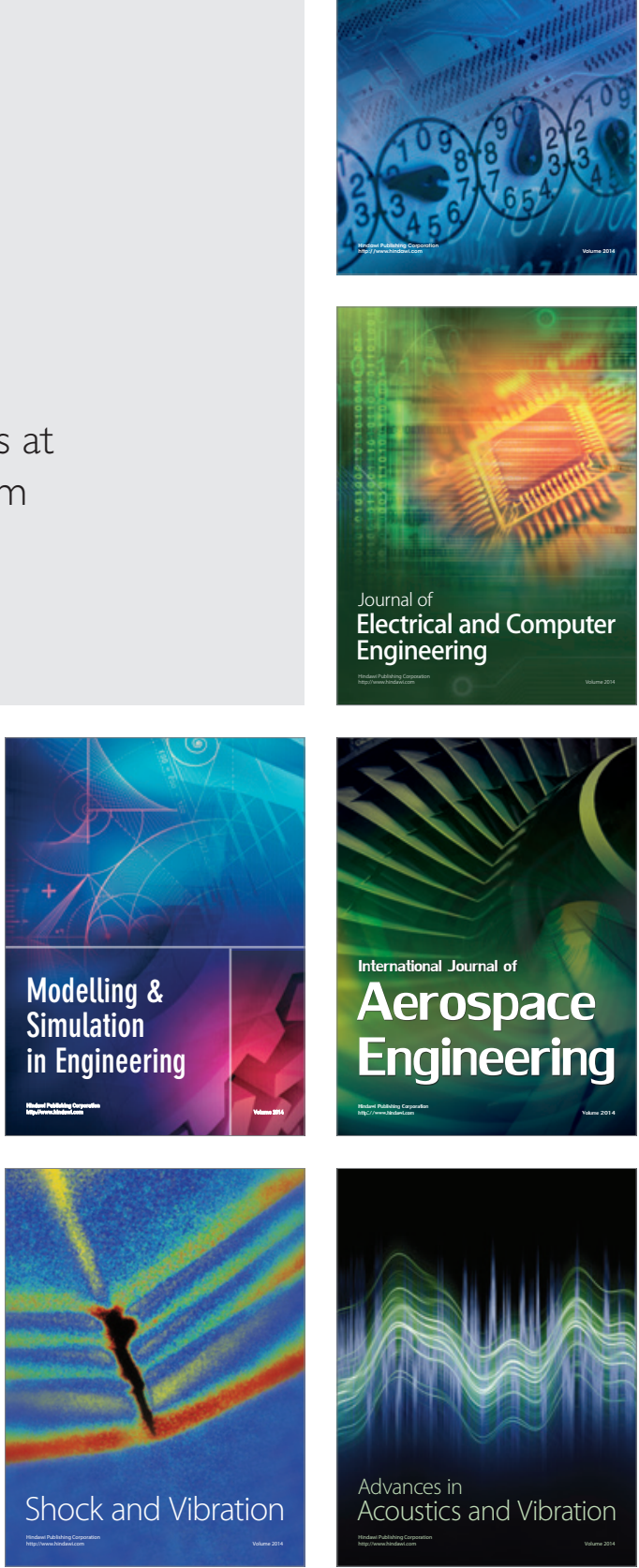